Int. J. Dev. Biol. 66: 9-22 (2022)

https://doi.org/10.1387/ijdb.210139id

\title{
Birth and death of neurons in the developing and mature mammalian brain
}

\author{
IOANNA DORI*, CHRYSANTHI BEKIARI, IOANNIS GRIVAS, \\ ANASTASIA TSINGOTJIDOU, GEORGIOS C. PAPADOPOULOS \\ Laboratory of Anatomy, Histology and Embryology, Faculty of Veterinary Medicine, School of Health Sciences, \\ Aristotle University, Thessaloniki, Greece
}

\begin{abstract}
Although neuron birth and death are two contradictory processes, they serve the same purpose of the formation of the brain. They coexist during brain development, when cytoarchitecture and synaptic contacts are progressively established. It is the highly programmed interplay between these two processes that results in the making of a mature, complex-wired, functional brain. Neurogenesis is the process that begins with the birth of naïve new neurons, which are gradually specified to their prospective cell fate, translocate through migratory streams to the brain area they are destined for, and terminally differentiate into mature neurons that integrate into neuronal networks with sophisticated functions. This is an ongoing process until adulthood, when it mediates brain neuroplasticity. Neuron death is the process through which the fine sculpting and modeling of the brain is achieved. It serves to adjust final neuron numbers, exerting quality control over neurons that birth has generated or overproduced. It additionally corrects early wiring and performs systems matching by negatively selecting neurons that fail to gain neurotransmitter-mediated neuronal activity or receive neurotrophic support for maintenance and function. It is also a means by which organizing centers and transient structures are removed early in morphogenesis. Both processes are evolutionary conserved, genetically programmed and orchestrated by the same signaling factors regulating the cell cycle, neuronal activity/neurotransmitter action and neurotrophic support. This review summarizes and highlights recent knowledge with regard to birth and death of neurons, the two mutually dependent contributors to the formation of the highly evolved mammalian brain.
\end{abstract}

KEYWORDS: neurogenesis, apoptosis, development, stem-cells, brain

\begin{abstract}
Abbreviations used in this paper: AMPA, a-amino-3-hydroxy-methyl-4isoxazolepropionic acid; aNSCs, actively proliferating neural stem cells; Apaf-1, apoptotic peptidase activating factor 1; Arc, activity-regulated cytoskeletal protein; aRGCs, apical radial glial cells; Bak, bcl-2 homologous antagonist/ killer protein; Bax, bcl-2-like protein 4; Bcl-2, B-cell lymphoma 2 pathway; BDNF, brain derived neurotrophic factor; $\mathrm{BF}$, basal forebrain; $\mathrm{BH}, \mathrm{BCl} 2$ homology domains; $\mathrm{Bid}, \mathrm{BH} 3$ interacting domain death agonist; BLBP, brain lipid-binding protein; BMPs, bone morphogenetic proteins; BPs, basal progenitors; BrdU, 5-bromo-2'-deoxyuridine; bRGCs, basal radial glia-like cells; Cdh, cadherin-8; CNS, central nervous system; DCX, doublecortin; DG, dentate gyrus; DISC, death-inducing signaling complex; dLGN, dorsal lateral geniculate nucleus; FADD, FAS-associated death domain protein; Fgf8, fibroblast growth factor 8; GABA, gamma aminobutyric acid; GCL, granule cell layer; GFAP, glial fibrillary acidic protein; GluR2, R2 subunit of the AMPA receptor; IPs, intermediate neural progenitors; IZ, intermediate zone; Ki67, proliferation marker Ki67; LV, lateral ventricles; ML, molecular cell layer; NCCD, Nomenclature Committee
\end{abstract}

on Cell Death; NeuN, neuronal nuclei; Neuro D, neurogenic differentiation factor; NGF, nerve growth factor; NMDA R1, R1 subunit of the NMDA receptor; NMDA, N-methyl-D-aspartate acid; Nrp1, neuropilin receptor 1; Nrp2, neuropilin receptor 2; NSCs, neural stem cells; NSE, neuron specific enolase; NT-3, neurotrophin-3; Pax6, transcription factor paired box 6; PCD, programmed cell death; PL, polymorphic cell layer; Prox1, prospero homeobox 1; PSA-NCAM, polysialylated neural adhesion cell molecule; qNSCs, quiescent neural stem cells; RGCs, radial glia cells; RGL, radial glia-like cells; Robo, roundabout receptors; Sema, semaphorin; SGZ, subgranular zone; Shh, sonic hedgehog; Sox1, SRY-box transcription factor 1; Sox2, SRY-box transcription factor 2; $S V Z$, subventricular zone; tBid, truncated form of $\mathrm{BH} 3$ interacting domain death agonist; Tbr1, T-box brain protein 1; Tbr2, T-box brain protein 2; TRADD, TNFR-associated death domain protein; TrKA, tropomyosin receptor kinase A; TrkB, tropomyosin receptor kinase B; TrkC, tropomyosin receptor kinase C; Tuj-1, beta-tubulin; TUNEL, deoxynucleotidyl-transferase-mediated dUTPbiotin nick end labelling; VZ, ventricular zone; Wnt, Wingless.

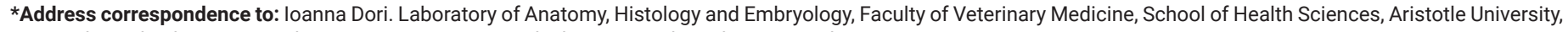
54124 Thessaloniki, Greece. Tel. +30-2310-999884. E-mail: idori@vet.auth.gr | https://orcid.org/0000-0003-0986-7826
}

Submitted: 6 July, 2021; Accepted: 25 August, 2021; Published online: 20 September, 2021.

ISSN: Online 1696-3547, Print 0214-6282

(C) 2021 UPV/EHU Press

Printed in Spain 


\author{
Birth and Death, \\ rumor has it, \\ are martyr lovers. \\ Their offspring, \\ unplundered Dreams or Lifers.
}

by G.C.P.

\section{Introduction}

Birth and death, two hallmark events of unsurpassed biological importance, represent not only the beginning and the end of all living units, but also the tools for the formation and shaping of the functioning brain. During embryonic development, multipotent neural stem cells (NSCs) undergo symmetric or asymmetric divisions to give rise to daughter cells that are either identical to their mother cells or destined to follow specific differentiation pathways leading to distinct cellular lineages, neuronal or glial. Programmed survival and death of these early generated cells mark the morphological and functional characteristics of the developing brain. Further sculpting of the functioning brain continues, but to a more limited extent, in the postnatal period. In the early post-embryonic and adult brain, neurogenesis appears to be a rather marginal phenomenon, limited to only few brain regions, with questionable implications, whereas gradually restricted natural neuronal death has been observed in a number of brain regions. Pathological activation of the death machinery has been regarded as a pathway leading to structural abnormalities and functional disabilities.

The subject domain of birth and death of brain neurons throughout the life span of mammalian species is unlimited and has attracted considerable attention of neuroscientists over the years. Exhaustive research from pioneering studies has provided a tremendous amount of evidence that has shed light on the generation of neuronal lineages, the development of brain cytoarchitecture and the establishment of neuronal circuitry; however, several aspects of this complex subject have yet to be elucidated.

In the present review, we summarize insights from state-ofthe-art investigations into the basic principles of neuron birth and death in the mammalian brain, highlighting the issue of these interrelated but often opposing processes during development and neuroplasticity of two telencephalic brain areas, the neocortex and the hippocampus. Both areas play a fundamental role in mammalian evolution and exhibit specific features with respect to neuron birth and death during development and maturity. The neocortex of the primate brain is involved in higher cognitive functions and represents the evolutionary step of acquiring a highly intricate neuronal circuitry. Accordingly, the hippocampus is the principal brain structure involved in learning and memory, with evolutionarily increasing capacity of cognitive flexibility.

\section{Birth of neurons in the mammalian brain during prenatal and early postnatal development}

The blueprints of the mammalian central nervous system (CNS) appear in the early embryo, during gastrulation, when part of the ectoderm is induced by the notochord to form neuroectoderm. Neuroectodermal cells located antero-dorsally form the neural plate, a homogeneous neuroepithelial layer. Cells in this layer display high mitotic activity and display specific gene expression patterns (Vieira et al., 2010). The mitoses are characterized by interkinetic nuclear migration, which makes the neuroepithelium a pseudostratified epithelial layer. The majority of neurons in the mammalian CNS are generated during embryonic and early postnatal development and originate from the initial pool of NSCs within the neuroepithelial layer. The birth of new neurons that are incorporated into neural circuits is termed neurogenesis. Cell fate determination is already set in the neural plate for the formation of the brain and spinal cord. Moreover, the fate maps of the forebrain, midbrain, hindbrain, and spinal cord are specified rostro-caudally in the neural plate (Wilson and Houart, 2004). This early patterning is regulated by various inductive signals, beginning with neuroectoderm induction mediated by a key signaling molecule of the Hedgehog family, the Sonic hedgehog (Shh) (Ozair et al., 2013). Many of the genetic factors that specify the neuroectoderm and the subsequent stages of neural morphogenesis are highly conserved among species.

Primary neurulation is the first part of a process that begins with neural plate formation, proceeds with its bending to form the neural groove, and is completed with the closure of the neural groove to form the neural tube (Smith and Schoenwolf, 1997). Neural tube closure is a complex event regulated by interactions between genetic and environmental factors. The wall lining the neural tube is threelayered, with the innermost layer being the primordium of all layers, termed germinal or ventricular zone (VZ). At the time of neural tube closure, its rostral end begins to expand to form the three primary brain vesicles: the forebrain, midbrain and hindbrain. Subsequently, the forebrain divides into the telencephalon and diencepahlon. Commencing in the early 1990s, a series of detailed analyses by Puelles and his colleagues has put forward the "prosomeric model" of brain development, according to which the forebrain at this stage is divided into spatially organized histogenic domains that correspond to specific zones of neural progenitors and morphogenetic gene expression patterns (reviewed in Vieira et al., 2010).

\section{Neurogenesis in the mammalian telencephalon}

The telencephalon initially appears as a paired set of forebrain pouches at the rostral end of the neural tube. It contains two germinal zones, the dorsal and the ventral VZ, termed as pallium and subpallium, respectively. The embryonic telencephalic subpallium is subdivided into the medial, lateral and caudal ganglionic eminence and anterior entopeduncular/preoptic domains. Cells in the germinal VZs proliferate, giving rise to daughter cells; hence these regions have also been termed the "proliferative zones" and comprise both neuronal and glial cell lines. Cells born in the pallium will give rise to cortical projection neurons and neurons of the olfactory bulb, whilst cells from the subpallium will become cortical interneurons and neurons of the hippocampus, the basal ganglia, the septum and the amygdala. These regions express homeobox transcription factors that regulate forebrain development (Hernández-Miranda et al., 2010).

The telencephalic VZ is composed of polarized neuroepithelial cells that continuously proliferate to form the cerebral vesicles. They first undergo symmetric, proliferative divisions for clonal expansion and establish the initial NSC pool. Once the phase of self-renewal divisions is complete, neuroepithelial cells proceed with asymmetric, neurogenic divisions to give rise to neuroepithelial cells and polarized apical radial glial cells (aRGCs), which are defined as the primary NSCs, as their progeny constitute all cell types in the CNS (Götz and Huttner, 2005). aRGCs also constitute the source of adult neurogenesis in neurogenic niches. 
Embryonic aRGCs increase their numbers in the VZ, dividing symmetrically, and at the peak phase of neurogenesis they undergo either direct neurogenesis, through asymmetrical neurogenic divisions to produce immature postmitotic neurons within the VZ, or indirect neurogenesis to generate basal progenitors (BPs) that are born at the surface of the VZ and then migrate to its basal layer. The continuous cell division within BPs results in the formation of a second proliferative zone that has been termed the subventricular zone (SVZ). Its outer section exhibits the highest proliferative capacity in primates, especially humans. The BPs comprise basal radial glia-like cells (bRGCs), and intermediate neural progenitors (IPs), which in turn proliferate in the SVZ to produce neurons (Taverna et al., 2014; Mira and Morante, 2020). It is generally accepted that the higher the phylogenetic order of mammalian species, the greater the diversity of neural progenitor cell populations. In lissencephalic mammals, such as rodents, IPs divide symmetrically for straightforward neuron production. In gyrencephalic primates, in which indirect neurogenesis is evolutionary selected, IPs ultimately give rise to a larger neuronal population, as they undergo a number of proliferative divisions before they differentiate. Additionally, the proportion of the bRGCs is higher in the latter species, where they produce IPs and neurons, at the same time replenishing their cell population and additionally co-expressing transcription factor paired box 6 (Pax6) and the T-box transcription factor Tbr2. This amplification process again adds to the final neuron number of the cerebral cortex (Uzquiano et al., 2018; Villalba et al., 2021). Progenitor cells that undergo neurogenic divisions have a longer cell cycle than cells that undergo proliferative divisions (Götz and Huttner, 2005). Several signaling pathways have been implicated in the orchestrating of these processes that are related to the cell cycle. The switch of symmetric, proliferative divisions to asymmetric, neurogenic ones is regulated by the evolutionary conserved Notch pathway, which balances stem cell proliferation and differentiation in the developing and adult brain (Engler et al., 2018) and a plethora of other signaling pathways and cell intrinsic factors (Villalba et al., 2021). Studies in transgenic mice have shown that Notch signaling is differentially regulated in NSCs and IPs (Mizutani et al., 2007). Notch activation imposes the stem cell-identity upon aRGCs, whereas Notch inhibition induces aRGCs for IPs production. The retention of the self-renewal-proliferative state is a neurogenic amplifying process. Mammalian brain development is also regulated by T-box genes. The Tbr 1 sub-family is important in development of the cerebral cortex, olfactory bulbs, and cerebellum. In a study of transgenic mice lacking the Tbr2 sub-family, deficient Notch signaling induced a RGCs response to increase direct neurogenesis that led to an earlier depletion of their initial pool (Mihalas and Hevner, 2017). The Wingless (Wnt) pathway stimulates initial aRGCs division, whereas at later stages it regulates neurogenic fate. Sox 1 transcription factor sets the timer for cell cycle exit by suppressing neurogenic divisions (Elkouris et al., 2011). Indirect neurogenesis, preferentially induced in phylogenetically higher mammals, is manifested by a precisely regulated, complex interplay of signaling factors, including Shh, Notch, Robo receptor signaling and Pax6 that regulate aRGCs' division mode and progeny fate (Villalba et al., 2021).

The duration of embryonic/early postnatal neurogenesis varies among mammalian species. It lasts longer in gyrencephalic than in lissencephalic mammals, attaining maximum levels in in humans, where it lasts approximately three months. This reflects the higher diversity of progenitor cells, contributing to the evolutionarily more intricate neuronal circuitry in primate brain.

\section{Neurogenesis in the mammalian neocortex}

A plethora of studies over the past decades have unraveled the intriguing issue of neocortical neurogenesis. Early autoradiographic studies suggested that the earlier born cells in the VZ are segregated in vertical columns, whereas the later born populations are organized in two horizontal bands, and this lamination corresponds to alternate fast and slow cycling stem cell populations (Altman and Bayer, 1990). It is now well documented that the production of cortical neurons occurs through indirect neurogenesis in the SVZ via neuronal amplification, which is most prominent in primates. The presumptive neocortex begins to form when newborn neurons that have exited the cell cycle in the SVZ migrate outwards to the cerebral vesicles, to form the preplate. This contains the earliest generated cortical neurons. When later born neural progenitors become postmitotic, they migrate out of the SVZ and split the preplate into the marginal zone and the subplate, which is separated from the VZ by the intermediate zone (IZ). Cortical layers are then formed in an "inside-out" pattern. According to this, the earliest born neurons reside at the deeper layers of the cortex, whilst neurons generated at later stages occupy more superficial layers, having migrated through the deeper layers to reach their final destination. This appears to be a common feature of mammalian cortical development (Parnavelas et al., 2002). Clonal analysis during mouse corticogenesis demonstrated three types of early IPs clonal differentiation: the first occurred through rapid terminal divisions following a couple of cell cycle rounds to produce infragranular-layer neurons; the second through asymmetric divisions with different laminar fates of daughter cells to produce neurons in multiple layers; and the third through divisions with delayed terminal differentiation to produce supragranular-layer neurons (Mihalas and Hevner, 2018). A relatively broad population of NSCs persists to adulthood, remaining in the SVZ as resident cells, with the transcriptomic identity of quiescent NSCs, until their neurogenic potential is re-activated during adult neurogenesis. This makes the SVZ the principal neurogenic niche in the adult brain.

The morphology and organization of neurons in the mammalian cerebral cortex has been extensively investigated since 1911, beginning with the work of Ramon y Cajal. Over the years, a tremendous amount of evidence from pioneering studies has shed light on the development, neuron lineages and establishment of connectivity. Cortical neurons are classified into two broad groups: pyramidal and nonpyramidal. These neurons show characteristic morphological and functional features. Pyramidal cells are projection neurons that use the excitatory amino acid glutamate as a neurotransmitter. Nonpyramidal cells are the local circuit cortical interneurons, which use the inhibitory neurotransmitter GABA (Parnavelas et al., 1989). Lineage studies have suggested that the telencephalic SVZ, which is the source of cortical neurons, contains a heterogenous population of BPs with different cell fates, determined by different mechanisms. Pyramidal and nonpyramidal neurons originate from progenitors in different regions, the pallium and the subpallium, respectively, then follow different migratory paths, radial or tangential, on their way to the primordial cortex. aRGCs have a dual function, the first fulfilling the role of multipotent primary NSCs, and the second providing scaffolding for guided neuronal migration. 
Strikingly, aRGCs have been shown to have a neurogenic potential, being the precursors of cortical pyramidal neurons. (Rakic, 2003). Neurogenic progenitors of pyramidal cells acquire initial positional information before they become postmitotic, but the acquisition of laminar fate specification is attributed to newborn neurons. In primates, these progenitors comprise IPs, as well as bRGCs. A cascade of the transcription factors Pax6, Neurogenin 2, Tbr2, Neuro D and Tbr1 is expressed at sequential stages from NSCs proliferation to pyramidal neuron production. The IPs have a distinct molecular profile, expressing the Tbr2 transcription factor. Studies on Tbr2 conditional mutant mice have shown that Tbr2 expression promotes the transition from IPs to neurons and the temporal order of cortical laminar identity acquisition. Pyramidal postmitotic neurons express the Tbr1 subfamily of T-box genes (Mihalas and Hevner, 2017). Newly postmitotic cells that will become cortical interneurons already express the LIM homeobox gene Lhx6 and cadherin-8 (Cdh8) within the subpallial medial ganglionic eminence. Mice lacking $C d h 8$ displayed a significant increase in the number of cortical interneurons, and in vitro studies confirmed that knockdown of $C d h 8$ induced proliferation of neural progenitors, whereas over expression of $C d h 8$ resulted in decreased proliferation (Memi et al., 2019). Interneuron progenitors also express the neuropilin receptors Nrp1 and Nrp2 that mediate their response to semaphorin (Sema) 3 ligands. Studies in semaphorin co-receptor PlexinA1 knockout mice showed a lower number of mature cortical interneurons, which was attributed to reduced proliferation of progenitor cells, due to their altered morphology and adhesion properties on the SVZ wall (Andrews et al. 2016). Further investigations in Nrp1 and Sema knockout mice demonstrated a size reduction of the NSCs pool in the subpallial medial ganglionic eminence that led to a decrease in the number of cortical interneurons (Andrews et al. 2017). Pyramidal postmigratory neurons originating from the same clone end up spatially related, whereas nonpyramidal neurons are dispersed as single isolated cells or pairs of clonally related neurons in the presumptive neocortex. (Parnavelas et al., 2002). The varying sizes of early IPs clones relate to the different rates between cell birth and death, while their laminar fates depend on neuron birthdates (Mihalas and Hevner, 2018).

\section{Neurogenesis in the mammalian hippocampus}

The hippocampal neuroepithelium consists of three neurogenic domains: the Ammonic neuroepithelium, giving rise to the pyramidal neurons of Ammon's horn; the primary dentate neuroepithelium, which is the source of the granule neurons of the dentate gyrus (DG); and the fimbrial glioepithelium-where glial cells of the fimbria are produced. In rodents, the Ammonic pyramidal neurons are born prenatally, whereas the birthdates of the majority of DG granule cells are postnatal (Altman and Bayer, 1990). The DG of the hippocampus is a key structure, exerting a central control on hippocampal functions. Along with the SVZ, the subgranular zone (SGZ) of the DG is a neurogenic germinal zone that persists into adulthood. During early neurogenesis, a population of neuroepithelial cells migrate to the SGZ and become resident quiescent NSCs with a neurogenic potential throughout postnatal life and in adulthood, reflecting a lifelong protracted development (Mira and Morante, 2020). It is, therefore, within the scope of this review to place the emphasis upon neurogenesis in this area.

The development of the DG is a temporally extended period. Neurogenesis begins at the primordial dentate neuroepithelium where NSCs proliferate to build up in clusters of progenitor cells in the SVZ. These proliferating cells form a new germinal zone, the neurogenic SGZ of the DG. The SGZ has been shown to be the source of the postnatally born granule cells in various mammalian species. Proliferative progenitors of granule cells then leave the SGZ and proceed along the dentate migratory stream to the primitive dentate structure (Altman and Bayer, 1990). These belong to two populations with different spatial distribution of their clonal origin in the SVZ, birthdates, migration patterns and final destination in the primordial DG. The cascade of transcription factors is similar to that expressed in neocortical neuron development. Proliferating neuroepithelial and IPs express the transcription factor Sox2, which regulates their proliferative divisions and neurogenic potential. IPs also express the transcription factor Tbr2, whereas postmitotic granule neurons express the transcription factors Prox 1 and Tbr1, which control the process of their differentiation (Seki et al., 2014; Mihalas and Hevner, 2017).

In rodents, most granule neurons are generated in the first postnatal week, and maturation of the DG is completed by the end of the second postnatal week. Progenitor cells first give rise to neurons destined to populate the polymorphic cell layer $(\mathrm{PL})$ of the DG. The molecular cell layer $(\mathrm{ML})$ is the next to be formed by cells that do not exit the cell cycle before the end of the first postnatal week. The latest born neurons give rise to the granule cell layer (GCL) and their birthdate is mainly a postnatal event. The $\mathrm{PL}$ and ML follow the neocortical "inside-out" pattern of formation, whereas the GCL is built by immature neurons in an "outside-in" sequential mode. Along its septo-temporal axis, the DG follows an "edge to center" pattern of formation, as granule cells arrive earlier at the temporal and then at the septal border than cells in the middle part (Altman and Bayer, 1990).

During recent decades, a plethora of studies has provided unequivocal evidence that mammalian species maintain the capacity of producing new neurons from multipotent quiescent NSCs during adulthood. Cell lineage studies have proposed the "sequential", the "set-aside" and the "continuous" model for neurogenesis in the maturing and adult brain in the two main neurogenic niches, the SVZ and the hippocampal SGZ. The latter model emerged from a recent study showing that in the mouse, DG granule neurons originate continuously and exclusively from a common progenitor pool in the developing and adult brain. This led to the assumption that adult neurogenesis may be regarded as "a life-long extension of development" that underlies the maintenance of hippocampal plasticity (Berg et al., 2019). The issue of whether neurogenesis in the adult brain is a distinct cellular process, or reflects an ongoing protraction of development, has yet to be resolved. In the context of eliminating the borders between developmental and adult neurogenesis, as suggested by Berg and colleagues (Berg et al., 2019), this review will next highlight the process of neurogenesis in the mature brain.

\section{Birth of neurons in the adult mammalian brain}

\section{Neurogenic niches of the adult mammalian brain}

Since the preliminary investigations into the occurrence of neurogenesis in the adult mammalian brain in the early 1960s, an abundance of studies, including these of our research team - using thymidine analog labeling, retroviral lineage, transcriptome analysis and single-cell profiling-have provided strong evidence that the SVZ 


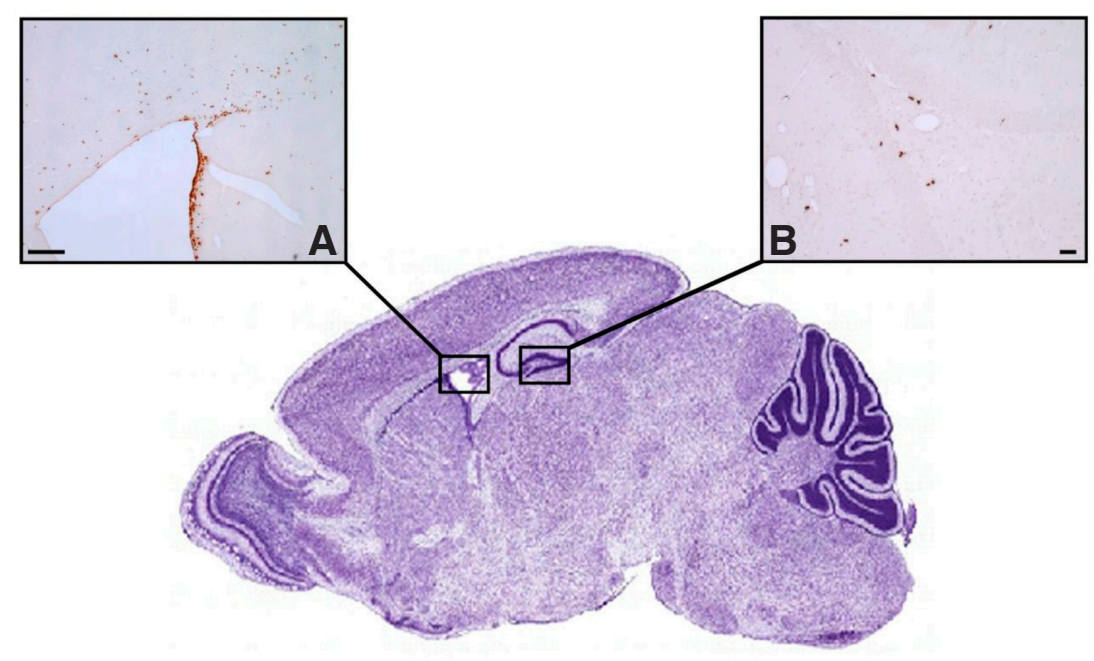

Fig. 1. Neurogenic niches of the adult mammalian brain. The SVZ of the lateral ventricles (A) and the SGZ of the hippocampal dentate gyrus (B) are the two principal neurogenic niches, shown to contain clusters of proliferating NSCs and their progenies that have incorporated the thymidine analogue bromodeoxyuridine (BrdU). Scale bars, $100 \mu \mathrm{m}$.

lining the lateral ventricles (LV) and the SGZ of the hippocampal DG are the principal neurogenic niches of the adult brain, showing homology across mammalian species (Fig. 1). Quiescent NSCs of embryonic origin that reside in the postnatal SVZ and SGZ become activated and give rise to new neurons and glia throughout adult life, although the rate and extent of neurogenesis is significantly reduced with increasing age.

Various environmentally derived signals, as well as intrinsic factors including gene expression and epigenetic reprogramming, activate the neurogenic potential of the resident quiescent NSCs in the neurogenic niches of the adult brain and support the maturation and functional integration of their progenies. Both niches display gap junction-mediated NSC contacts, contain an extracellular matrix rich is neurogenic molecules, a high number of astrocytes that exert a positive or negative regulation on the neurogenic activation of NSCs, a rich network of vasculature that is contacted by NSCs, and lie in close proximity with neurogenesis-supporting areas (i.e. the ependymal cell layer between the SVZ and the LV).

Additionally, the same morphogens and transcription factor cascades that guide neurogenic and proliferative divisions and cell fate specification during embryonic development also regulate adult neurogenesis. Despite their lack of synapses, NSCs' neurogenic potential is also affected by neurotransmitters. For example, GABA and dopamine inhibit activation of NSCs, whereas serotonin and acetylcholine have the opposite effect. The sources of newly produced neurons are multipotent NSCs, pluripotent neural progenitor cells, or even epigenetic cell fate reprogrammed astrocytes (Bond et al., 2015; Obernier and Alvarez-Buylla, 2019; Griffiths et al., 2020).

The existence of novel neurogenic regions in the adult brain, other than the SVZ and SGZ, is currently the object of thorough investigation. Various areas of the adult brain, which are massively impaired in neurodegenerative disorders, have been examined for their possible neurogenic potential, and populations of adultborn neurons were found to exist in the hypothalamus, striatum, substantia nigra, cerebral cortex and amygdala. Lineage-tracing studies suggested that tanycytes, a population of specialized RGCs that reside at the wall of the third ventricle and at the median eminence of the hypothalamus, comprise a population of potential NSCs. The presence of neuroblasts in the adult striatum was regarded as an indicator of the local ongoing neurogenesis. However, it was argued that adult-born neurons localized in the human striatum may originate from proliferating NSCs in the adjacent SVZ and then migrate to form striatal interneurons. Moreover, it has been suggested that neurogenesis in these brain regions is triggered by pathological processes such as stroke/ischemia and neurodegenerative disorders. (Jurkowski et al., 2020). The question whether the above mentioned brain areas have the ability to generate new neurons in the healthy adult brain or represent migrating sites of neuroblasts born in the principal niches, mainly under pathological conditions, awaits elucidation.

\section{Neurogenesis in the SVZ of the adultmammalian brain}

The SVZ is the major neurogenic germinal zone in the adult mammalian brain, as it hosts the broader pool of NSCs. Recent studies using large-scale single-cell profiling, demonstrated that adult NSCs in the SVZ comprise: a) the RGCs with astrocytic features, that display regional specification related to a distinct lineage potency for either neuron, or glial cell production and b) a subpopulation of B progenitors (B1 cells), derived from embryonic aRGCs, and capable of both self-renewal and neurogenic divisions. Both cell types exhibited a heterogeneous neurogenic fate potential. These data confirmed and extended previous transcriptome analysis that suggested regional-specific differences in lineage commitment at the molecular level, in this area. With respect to the activity state, the SVZ contains two populations of NSCs, the quiescent (qNSCs) and the actively proliferating (aNSCs). According to the "set aside" model for neurogenesis, once generated prenatally, NSCs destined for the adult SVZ pool switch to a quiescent state until adulthood, and do not produce neurons. The neurogenic aNSCs give rise to transient amplifying IPs, also known as $C$ cells, which are the most actively dividing cells of the SVZ. They express nestin and are localized in clusters along the LV wall. C cells undergo amplification divisions and then produce immature neurons, also named $A$ cells, that express the polysialylated neural adhesion cell molecule (PSA-NCAM) and beta-tubulin (Tuj-1) and migrate through the rostral migratory stream to become different subtypes of olfactory bulb interneurons (Mizrak et al., 2019). In the adult brain, factors that control the symmetric and asymmetric divisions of aNSCs and their subsequent differentiation, with a different origin from those acting during development, are derived from the local cellular microenvironment, the cerebrospinal fluid, the local blood vessels, and neurotransmitter input from adjacent or remote brain areas. Although neurogenesis in the adult SVZ is driven by a heterogenous NSCs population and is regulated by adult-specific mechanisms, it has been proposed that regional specification is pre-established in embryonic development and is inherited by the adult NSCs (Obernier and Alvarez-Buylla, 2019).

\section{Neurogenesis in the SGZ of the adult mammalian brain}

Ongoing neurogenesis in the SGZ of the adult hippocampus has attracted increased attention due to its association with neuroplasticity-mediated functions in healthy and pathological 

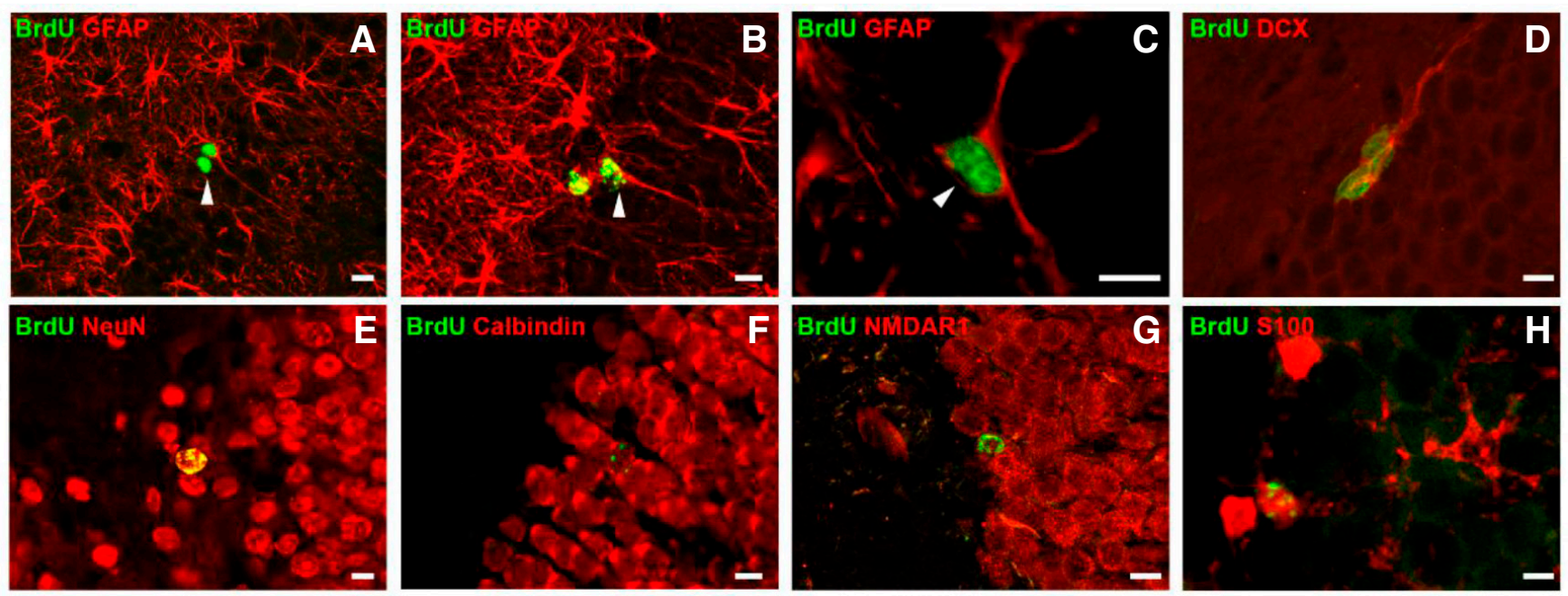

Fig. 2. Radial glia-like NSCs and their neuronal and glial progenies in the hippocampal DG of the adult rat brain. Brdu ${ }^{+}$radial glia-like NSCs (arrowheads in A-C) divide symmetrically or asymmetrically and give rise to new neurons (A), new astrocytes (B) and new radial glia-like NSCs (C). Newborn neurons and astrocytes express stage-specific markers during their sequential differentiation and maturation phase. Differentiating newborn neurons express the marker DCX (D), which is followed by expression of the more mature neuronal marker NeuN (E). Mature newborn granule cells are immunoreactive for calbindin (F) and have developed NMDA receptors (G). Mature newborn astrocytes express the astrocytic marker S100B (H). Scale bars, $10 \mu \mathrm{m}$. (Re-used with permission of John Wiley and Sons, from Bekiari et al., Hippocampus 25: 511-523, 2015).

brain. According to the recently proposed "continuous" model for neurogenesis, in the developing and adult brain, new neurons of the DG originate continuously and solely from a common neural progenitor population in the germinal SGZ, arising from a population of neuroepithelial cells that have migrated to the SGZ since early neurogenesis, divide until the DG is formed, before acquiring quiescent radial glia-like (RGL) features postnatally. This is different from the "set aside" model of neurogenesis that occurs in the SVZ (Berg et al., 2019). In the SGZ, RGL cells express the transcription factors Sox2 and Pax6 as well as the astrocytic cell marker GFAP. Upon activation, they down regulate niche-ligand receptors, downstream signaling factors and divide symmetrically or asymmetrically to give rise to progenitors of either the neurogenic or the astogliogenic lineage and, at the same time, to self-renew and replenish their initial pool, avoiding their rapid deforestation. The transcription factor cascade that characterizes early neurogenesis is maintained in the adult (Bond et al., 2015; Mihalas and Hevner, 2017). From birth to adulthood, dentate neural progenitors display downregulation of cell cycle-gene expression, transcriptional and translational adjustment and upregulation of gene expression involved in processes related to cell surface signaling, oxidation reduction, and lipid metabolism (Berg et al., 2019).

Using a combination of the thymidine analogue 5-bromo-2'deoxyuridine (BrdU) with multiple cell-specific markers, our research team undertook a detailed investigation into the fate of adult-born neurons in the rat DG, from their birth to their full maturation (Bekiari et al., 2015a) (Fig. 2). Neural progenitors, which originate from the RGL NSCs, continue to express markers of the radial glial cell lineage (Sox2, Brain lipid-binding protein/ BLBP) and progressively become positive to markers and transcription factors of the neuronal lineage (nestin, doublecortin/ DCX, PSA-NCAM, neuronal differentiation factor D/ NeuroD, Musashi-1 and Tbr2 transcription factor), while they lose their capacity of proliferation. Newborn neurons during their early immature state are still immunoreactive for DCX, PSA-NCAM and NeuroD, and from the third post-mitotic day, they start to express the neuronal marker neuronal nuclei (NeuN), while about 3 weeks post-mitosis they also express calbindin. All calbindin-containing mature granule cells are immunoreactive for the N-methyl-D-aspartate acid (NMDA) receptor subunit R1 (NMDA R1) and for the a-amino-3-hydroxy-methyl-4-isoxazolepropionic acid (AMPA) receptor R2 subunit (GluR2). Although the calcium binding protein calretinin is expressed in immature neurons of the adult murine $D G$, our findings revealed that newborn neurons of the adult rat and canine DG were negative for calretinin, at all time-points examined, from day 2 until day 30 postnatally, which is consistent with previous findings in non-human primates (Bekiari et al., 2015a; 2020).

\section{Neurogenesis along the septo-temporal axis of the DG of the adult mammalian brain}

Hippocampal DG is not a homogeneous structure along its septo-temporal axis. There are reports on variations in embryonic development, cytoarchitecture, gene expression, neurochemistry and connectivity along the DG septo-temporal axis that lead to the functional discrimination of the two DG poles (reviewed by Bekiari et al., 2015b) and may be responsible for differences in the ongoing neurogenesis process.

The quiescent or the proliferative state of NSCs in the SGZ of the adult hippocampus was found to be affected by both blood- and endothelial cell-derived factors of the rich and highly organized local vasculature. Vascular endothelial growth factor supports NSC proliferation, whereas neurotrophin 3 acts in favor of quiescence (Bond et al., 2015). Members of our research group demonstrated a septo-temporal heterogeneity of the vascular network, with the septal DG displaying a higher capillary density than temporal DG (Grivas et al., 2003). Taken together, these data suggest a possible differential regulation of neurogenesis between the septal and temporal poles of the DG.

Evaluation of higher numbers of newborn $\mathrm{BrdU}^{+}$cells in the septal part of the adult DG was indicative of higher levels of neurogenesis 
in this area (Snyder et al., 2012). However, when we performed a parallel stereological analysis of the newborn BrdU+ cells and the total granule cell populations of the two dentate parts in the rat hippocampus, we found an equal neurogenic potential of the septal and temporal part (Bekiari et al., 2015a). In the adult canine DG, however, similar stereological counting revealed an increased neurogenic potential of the septal DG part, which was attributed to the higher number of locally dividing radial glia-like NSCs (Bekiari et al., 2020). In both mammalian species studied, the developmentally 'older' temporal DG part showed an increased potential for viability of newborn neurons, achieving a balance between the birth rate of new neurons and their accession into the local neuronal circuits.

Adult-born neurons of the septal DG were shown to acquire a more mature neuronal phenotype earlier (Snyder et al., 2012). Electrophysiological studies showed the rapid loss of immature neuronal properties, while immediate-early genes (Arc) expression profiles revealed an earlier neuronal activity of the septal neurons. Our marker expression studies support this notion by showing that newborn neurons of the septal DG manifested earlier expression of neuronal markers (DCX, NeuN) and earlier acquisition of glutamate receptors (NMDA R1 and GluR2), in both the rat and canine DG (Bekiari et al., 2015a; Bekiari et al., 2020). Notably, there was a profound delay in the maturation time of adult-born neurons of the canine DG compared with the rat DG, which was anticipated by similar findings in other gyrencephalic species, such as the sheep and non-human primates.

A region-specific effect on the functional outcome of adult-born neurons has also been documented. Following the functional segregation of the septal and temporal DG part, newborn neurons of the septal DG appear to contribute to certain aspects of the spatial learning process, whereas immature neurons of the temporal DG are involved in the anxiolytic-related effect of chronic antidepressant treatment (Wu and Hen, 2014).

\section{Neurogenesis in the adult brain across mammalian species}

Adult neurogenesis in brain germinal zones is widely conserved throughout phylogeny, and although the consecutive steps from neuron production to their maturation share similarities across mammalian species, certain species-specific differences are noted with respect to the extent and rate of neurogenesis.

Neurogenesis in the adult rodent brain is the most extensively studied, and significant variations between rodent species were found to exist in adult hippocampal neurogenesis. Adult-born hippocampal granule cells achieve morphological and functional maturity earlier, have a better chance of survival and are more likely to participate in learning behavior in rats, compared with mice (Snyder et al., 2009).

Evidence suggests that the neurogenic potential of the adult brain differs between primate and non-primate mammalian species. Comparisons between the rodent and primate brain showed that in the former the neurogenic potential of NSCs in brain niches remains unchanged throughout adulthood, in contrast to the latter, where neurogenesis is significantly reduced after the first postnatal years (Kohler et al., 2011; Isaev et al., 2019). Co-labeling of newborn BrdU+ cells with neuronal markers demonstrated that maturation of adult-born neurons in rodents is already achieved one month after BrdU injection, both in the olfactory bulb and the DG; in the adult sheep hippocampus, meanwhile, new neurons do not mature until four months after their genesis, and in non-human primates, the respective maturation time may exceed six months (Kohler et al., 2011; Brus et al., 2013).

Canines are gyrencephalic animals with high translational value in the study of age-related neurodegenerative disorders and affected hippocampal neurogenesis, as their aging brain exhibits many pathophysiological changes that resemble those of human brain. Numbers of newborn BrdU ${ }^{+}$cells, proliferating Ki67-positive cells and DCX-expressing neuroblasts in the canine SGZ showed a significant age-related decrease that was directly correlated with cognitive decline (Siwak-Tapp et al., 2007). In a detailed study, we provided a description of the cellular and temporal characteristics of the sequential steps of neurogenesis in the adult canine hippocampus. Based on the evaluation of these data in conjunction with reports on the adult rodent and non-human primate DG neurogenesis, we assumed that dynamic changes in the numbers of canine proliferating radial glia-like NSCs and adult-born granule cells closely resemble these of other gyrencephalic species, although, to some extent, they also bear similarities to features of adult rat DG neurogenesis (Bekiari et al., 2020).

Whether neurogenesis persists in remarkable levels in the adult human brain or is dramatically decreased after birth is at present a matter of controversy. The occurrence of newborn $\mathrm{BrdU}^{+}$cells, which co-expressed neuron specific markers (NeuN, calbindin and neuron specific enolase/ NSE), was initially shown in the postmortem human hippocampus (Eriksson et al., 1998). Later tissue culture studies confirmed the multipotency of NSCs in the SVZ and SGZ and their ability for self-renewal, whilst their birth dating through quantification of their ${ }^{14} \mathrm{C}$ levels revealed that almost 700 new neurons are added in each hippocampus per day (Spalding et al., 2013). A more recent unbiased stereological quantification of adult-born neurons in the entire human postmortem hippocampus reported similar numbers of neural precursor nestin-expressing cells, mature granule cells and glia in the DG of healthy juvenile, adult and elderly individuals, confirming that hippocampal neurogenesis not only exists, but is also maintained throughout the lifespan (Boldrini et al., 2018). What makes the adult different from the developing brain in humans is that adult-born neuroblasts in the SVZ migrate to the adjacent striatum to form new interneurons and do not move to the olfactory bulb, which is also different from equivalent data in rodents and other mammalian species. In contrast with the above findings are reports supporting that neurogenesis in the adult human brain is rare or completely absent. RNA-sequencing studies support the lack of neurogenesis in the adult human DG, and immunohistochemical studies showed that DCX-positive cells of the adult human DG have mature morphology and thus do not represent newborn immature neurons, as previously believed (Sorrells et al., 2021). All these controversial findings, which may under- or over-estimate neurogenesis in the adult human brain, could be attributed to several methodological and technical limitations encountered when studying postmortem human brain tissue.

\section{Role of neurogenesis in the adult mammalian brain}

The expanding field of adult stem cell biology and brain neuroplasticity has provided invaluable insights into translational neuroscience and regenerative medicine. The brain's ability to produce new neurons throughout postnatal development and in adulthood underlies neuroplasticity, a fundamental capacity of the 
brain. This process involves maintenance of brain integrity and at the same time support of structural and functional alterations of the existing neuronal circuitry that enable functional adaptation to the changing environment. Neuroplasticity underlies learning, memory and mood regulation functions, as well as repair and regeneration mechanisms after brain injury or neurodegenerative disorders. It has been proposed that adult neurogenesis is involved in complex tasks of improved cognitive flexibility, such as longterm spatial memory, pattern separation, behavioral modulation of stress, as well as metabolic and olfactory adaptations. Impairment of adult neurogenesis is associated with several pathologies and concomitant cognitive dysfunction (Anacker and Hen, 2017; Jurkowski et al., 2020).

\section{Regulation of neurogenesis in the adult mammalian brain}

Adult neurogenesis is regulated by the interaction of extrinsic and intrinsic factors. Studies on the human brain have shown that the intrinsic factors may be epigenetic (DNA methylation, histone post-translational modifications and chromatin remodeling), transcriptional (transcription factor-mediated survival, proliferation, cell fate specification, differentiation and integration of NSCs and their progenies) and metabolic (reviewed by Niklison-Chirou et al., 2020).

The extrinsic regulators of neurogenesis include various physiological, pathological, and pharmacological factors. Certain physiological stimuli, including environmental factors and exercise, are presumed to be positive regulators of neurogenesis that induce a neurogenic response of NSCs in germinal niches. By contrast, aging and neurodegenerative disorders of the CNS have a negative effect on neurogenesis, leading to the cognitive decline of the elderly and pathological brain. Both processes lead to a decrease in neurogenesis. However, in normal aging, the morphological and functional properties of newly formed neurons are not altered, whereas neurodegenerative mechanisms lead to considerable neuron death in the areas affected. A substantial body of evidence underlines the impact of aging, brain injury and neurodegenerative brain diseases on both neurogenesis and neuron death. The present review, however, deals only with the healthy, normally maturing brain, so the presentation of data on the aging and pathological brain transcends our mission.

With respect to the advantageous manipulation of adult neurogenesis, recent evidence suggests that early environmental enrichment results in long-lasting beneficial effects in hippocampal neurogenesis, behavior and epigenetics (Zocher et al., 2020). Even short-term enrichment periods were shown to increase cell proliferation in the hippocampus and improve performance in behavioral testing, although the magnitude of these effects decreased with age (Chandler et al., 2020).

Additionally, seeking to investigate the effects of various experimental interventions on neurogenesis, we have previously quantified neurogenesis in the SVZ and SGZ, after intraventricular transplantation of adipose-derived mesenchymal stem cells in the adult rat brain. Our estimates showed that transplantation induced a significant increase of the number of newborn neurons (absolute number of $\mathrm{BrdU}^{+}$cells) in both niches. In line with reports from other studies, this was attributed to the mobilization of endogenous NSCs, through the neuromodulatory action of exogenous stem cells on the microenvironment of adult brain germinal zones (Fig. 3), (Dori et al., 2017).
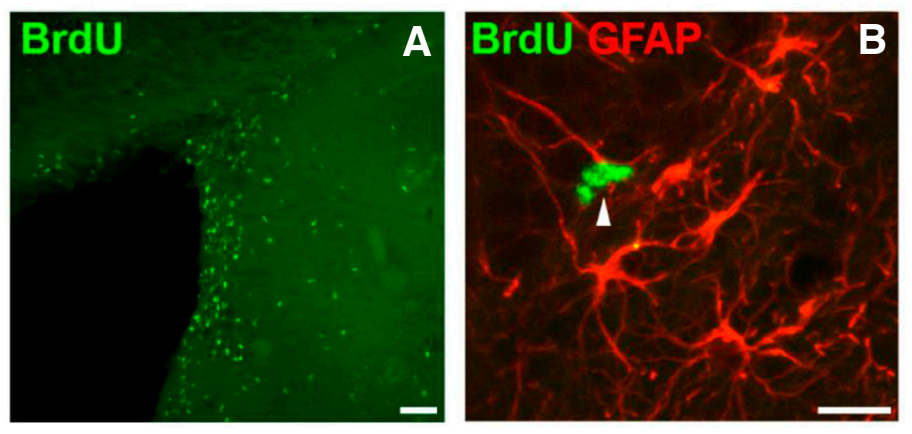

Fig. 3. Experimentally induced neurogenesis in the SVZ of the adult rat brain. After intraventricular transplantation of mesenchymal stem cells, numerous Brdu+NSCs are localized in the SVZ (A) and comprise RGCs with astrocytic features, expressing GFAP (arrowhead in B). Scale bars, 50 $\mu \mathrm{m}$.

\section{Death of neurons in the mammalian brain during prenatal and early postnatal development}

Mammalian brain development involves a precise sequence of genetically controlled processes, such as NSC proliferation, migration, differentiation and death. These developmental events are not unique to mammalian neural development, as they are underlined by key mechanisms conserved during evolution. A developmental overproduction of neurons takes place, a considerable number of which are driven to death before they reach maturity. This developmental cell death is ubiquitously under strict temporal and spatial regulation and is referred to as «programmed cell death» (PCD). Apoptosis, a term derived from the Geek word meaning "detaching and falling off" is the main type of developmental PCD, which involves the elimination of the excess number of cells. It is a key event in brain development, playing a crucial role in the control of cell numbers, quantitative matching, and the establishment of neuronal circuitry (Burek and Oppenheim, 1996). Apoptosis in neural development has been observed in a variety of invertebrate and vertebrate species, including insects, amphibians, fish, birds and mammals (see Yeo and Gautier, 2004, for review). It is thus regarded as an evolutionary-conserved developmental mechanism, designed to optimize nervous system size and connectivity (Dekkers et al., 2013). This process is area-specific and related to the cell type. Genetic studies have shown that changes in the interplay between neuronal cell birth and death may have contributed to mammalian brain evolution (Vallender and Lahn, 2006).

\section{Morphological features of apoptotic cell death}

Light and electron microscopic studies have revealed that the morphological features typical of apoptosis include internucleosomal DNA fragmentation, a pyknotic nucleus showing chromatin condensation and often rounded chromatin clumps, a shrunken cytoplasm with destructed cytoskeleton, intact plasma membrane blebbing and detachment of the cell from the surrounding tissue. At the end of the process, membrane-bound apoptotic bodies are cleared by phagocytic cells (Kerr et al., 1972). DNA fragmentation leads to the formation of low-molecular weight DNA oligomers that can be visualized after DNA isolation and electrophoresis, or in situ by the use of the terminal deoxynucleotidyl-transferase-mediated dUTP-biotin nick end labelling (TUNEL) method. Apoptotic cell death is executed via molecular pathways that are mediated by 
the activation of caspases, a family of cysteine proteases. These have been suggested to mediate apoptosis in both NSCs and post-mitotic neurons (Hollville et al., 2019).

\section{Mechanisms of apoptotic cell death}

According to the Nomenclature Committee on Cell Death (NCCD), two molecular pathways of apoptosis are distinguished, the intrinsic, or mitochondrial, or Bcl-2-regulated pathway and the extrinsic or death receptor pathway (Galluzzi et al., 2018). Intrinsic apoptosis is triggered by various perturbations of the intracellular or extracellular microenvironment, including DNA damage, endoplasmic reticulum stress, reactive oxygen species overload, mitotic defects or growth factor elimination. Intrinsic apoptosis involves irreversible mitochondrial outer membrane permeabilization, which is controlled by pro-apoptotic and anti-apoptotic members of the Bcl2 apoptosis regulator protein family, a group of proteins sharing one to four $\mathrm{Bcl} 2$ homology $(\mathrm{BH})$ domains. The pro-apoptotic members Bax and Bak are activated transcriptionally or post-translationally and constitute the main executors of the intrinsic pathway, as they are responsible for the formation of pores in the outer mitochondrial membrane. However, this is the case for postmitotic, differentiating neurons, as proliferating progenitors undergo apoptosis in a Baxindependent pathway. Bax knock-out mice showed a total absence of apoptosis of postmitotic neurons in the CNS (Jung et al., 2008). Mice lacking both bax and bak genes displayed multiple developmental defects, including surplus cells within the CNS (Lindsten et al., 2000). Membrane permeabilization results in the release to the cytosol of apoptogenic factors, such as cytochrome c, HtrA2/ OMI, Smac/Diablo, apoptosis inducing factor, and endonuclease G, which normally reside in the mitochondrial intermembrane space. The cytosolic cytochrome $c$ binds to apoptotic peptidase activating factor 1 (Apaf-1) and pro-caspase 9 in a deoxyATP-dependent manner to form the apoptosome that activates caspase 9 , which then catalyzes the proteolytic activation of caspases 3 and 7, the executioners of apoptosis. As development proceeds, the intrinsic apoptotic pathway progressively declines, as implied by the reduction in Apaf-1 and caspase-3 gene expression and this may reflect an anti-apoptotic protection mechanism in the mature brain (Galluzzi et al., 2018).

Extrinsic apoptosis is triggered by various perturbations of the extracellular microenvironment, mediated either by death receptors, whose activation depends on ligand- binding, or dependence receptors, which are activated when the levels of their cognate ligands drop below a specific threshold. This results in recruitment and activation of caspase- 8 or -10 , through the death-inducing signaling complex (DISC), comprising the FAS-associated death domain protein (FADD) and/or TNFR-associated death domain protein (TRADD). Activated caspase-8 then activates downstream effector caspases by proteolytic cleavage of the $\mathrm{BH} 3$, interacting domain death agonist (Bid) to produce the truncated form tBid, which translocates to mitochondria to induce Bax activation (Galluzzi et al., 2018). The family of dependence receptors during brain development includes the neurotrophin receptor TrkA for nerve growth factor (NGF) and TrkC for neurotrophin-3 (NT-3) which may initiate apoptosis by the proteolysis of the neurotrophin receptor p75NTR for BDNF, with which they are associated. A number of studies have revealed that the survival of most brain neurons depends not only on single growth factors, but also on various components of the cell death machinery that play a critical role in the establishment of neuronal circuitry (Nikoletopoulou et al., 2010; Dekkers et al. 2013).

It has been well documented that the apoptotic elimination of surplus cells in the CNS during development is biphasic, involving different cell populations and serving different functions: one phase occurs prenatally and involves proliferating neural progenitors and newly postmitotic neuroblasts, and the other postnatally, affecting exclusively postmitotic neurons in the process of their incorporation into neuronal circuits.

\section{Apoptotic neuron death in the mammalian brain during prenatal development}

The earliest apoptotic cell death in the mammalian CNS begins during neurulation, within the neural ectoderm, mainly at the anterior neural ridge, its rostral borders with superficial ectoderm. The anterior neural ridge acts as an organizer by producing Fgf8 morphogen, which leads to the formation of the neural tube, the primordial brain and spinal cord. Dying cells spread in the presumptive hindbrain neural folds during and after the neural tube closure (Yeo and Gautier, 2004; Yamaguchi and Miura, 2015). The neuroepithelium consists of proliferating NSCs that exit the cell cycle and begin specification to neuronal lineage only after neural tube closure. Apoptosis at these early stages of prenatal ontogenesis, associated with populations of undifferentiated NSCs and neural progenitors, reflects a measure of quality control and serves the purpose of the initial morphogenetic sculpting of the CNS. It has been suggested that apoptosis induces tissue remodeling during neuroepithelial morphogenesis, and modulates the speed of neural tube closure (Ambrosini et al., 2017). Inhibition of apoptosis in transgenic mice disturbs neural morphogenesis, and can lead to neural tube closure defects. In apoptosis-deficient mutant mice, Fgf8-expressing cells persist in the anterior neural ridge, impairing gene expression in the ventral forebrain and leading to brain malformations (Nonomura et al., 2013).

In subsequent embryonic stages, high rates of apoptosis were noted within the brain SVZ and involved the daughter cells of early IPs, destined to become cerebral cortical neurons (Thomaidou et al., 1997). During neurogenic divisions of early IPs, asymmetric apoptosis of IP daughter cells occurs in synchrony to the different modes of division for clonal specification. This implies that while one daughter cell proceeds with division and differentiation, the other cell dies. Considering that the cell fate specification of early IP clones is mediated in relation to the fine balance between cell birth and death in the germinal zones, it has been hypothesized that these apoptotic binary death events might represent a mechanism regulating clonal expansion (Mihalas and Hevner, 2018). The significance of the linkage of binary apoptosis to asymmetric cell divisions is not fully clarified and requires further investigation; to date, however, apoptosis is regarded as an evolutionary conserved asymmetric fate choice of many IP daughter cells (Hevner, 2019).

What determines the dilemma between life and death in cells during early neural development? It has been documented that diverse and often conflicting developmental processes are regulated by the same classes of molecules. Several factors that regulate cell cycle, patterning, growth, cell fate determination and terminal differentiation are also involved in the control of cell death during early neural development. In the proliferating neuroepithelium of the developing rat cerebral cortex, apoptosis is related to the progression of the cell cycle (Thomaidou et al., 1997). Pharmaco- 
logically induced mitotic delay induces apoptosis in progeny of neural progenitors (Pilaz et al., 2016). It is the balance between cell proliferation and death, as well as the coupling mechanisms of these processes, that eventually controls cell numbers (Juraver-Geslin and Durand, 2015). It has been proposed that the orchestrated action of a variety of morphogens regulates proliferation and apoptosis in the developing brain. Bone morphogenetic proteins (BMPs) are involved in cell fate determination in the neural tube, the maintenance of proliferation, mitotic exit, and subsequent differentiation of neural precursors. Wnt proteins are involved in the regulation of the balance between apoptosis and proliferation of neural progenitors. Wnt-mediated patterning of the neural tube occurs downstream of the BMP pathway (Panchision and McKay, 2002). Initial studies in the chick embryo that were later extended to mice have shown that Sonic hedgehog (Shh) protein acts as a graded signal to control the patterning and neural progenitor cell fate determination in the posterior ventral neural tube (Placzek and Briscoe, 2018). Cells engineered to produce Shh protein have an anti-apoptotic role at the early stages of brain morphogenesis in in situ grafts and transplantation experiments (Charrier et al.,

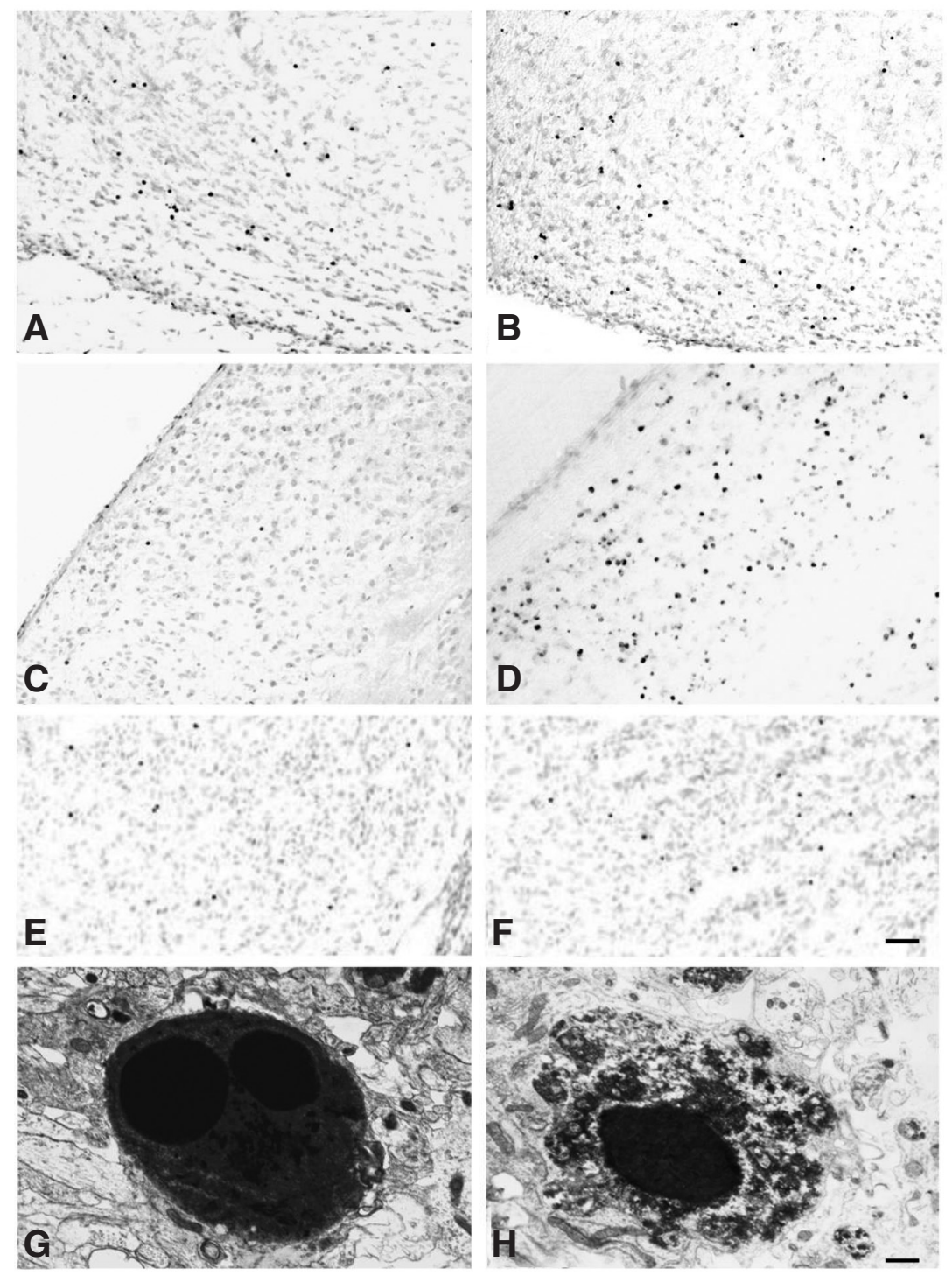

2001). In fact, during neural morphogenesis, all cells possess the apoptotic machinery, but require anti-apoptotic signals in order to survive. Many neuron survival pathways eventually converge on pro-apoptotic and anti-apoptotic members of Bcl2 family and caspases (Pfisterer and Khodosevich, 2017).

\section{Apoptotic neuron death in the mammalian brain during postnatal development}

The critical period during which neurons in the developing brain are prone to cell death is when they start to establish synaptic contacts. At this stage, cell survival depends on neuronal activity via the action of neurotransmitter input, which regulates the expression of growth factors (Dekkers et al. 2013). Blocking of glutamate NMDA receptors, or the excessive activation of gamma-aminobutyric acid (GABA) receptors, during the period of synaptogenesis, induces neuronal apoptosis in the developing mammalian brain (Ikonomidou, 2009). However, apoptosis of a large number of interneurons is induced by intrinsic mechanisms that are independent of extrinsic triggers (Dekkers and Barde, 2013). It thus appears that the regulation of developmental apoptosis is neuron type-specific. Apoptosis of immature neurons that are generated in the brain during prenatal development is more profound around the time of birth. The critical period for survival of neurons born postnatally lasts approximately four weeks, and thereafter they become resistant to cell death (Pfisterer and Khodosevich, 2017).

We have undertaken a series of studies in which we employed caspase 3 immunohistochemistry and the TUNEL method to investigate apoptosis in the rodent brain during postnatal development. Our results demonstrated that in all brain areas examined, a number of cells die during the first month after birth, showing early high frequency periods. Using double labeling with cell-specific markers and electron microscopy, we confirmed that this death is apoptotic and involves postmitotic neurons (Figs 4 and 5). In the basal forebrain (BF), apoptotic cells were present during the first two postnatal weeks, showing two peaks, at postnatal day (P) 1 and at P5 (Sophou et al., 2006). In the striatum, apoptotic cells were observed during

Fig. 4. Photomicrographs and electron micrographs of apoptotic cells in the rat brain, during normal development and following lesions of connections. The distribution pattern of $\mathrm{TUNEL}^{+}$cells in the basal forebrain at birth (A) was not altered following neonatal lesions of connections and examined 1 day post-lesion (B), in contrast to the dorsal lateral geniculate nucleus, in which the total number of TUNEL ${ }^{+}$cells increased dramatically 1 day after neonatal lesions (D), compared with their number in the normal, developing brain (C). The distribution pattern of TUNEL ${ }^{+}$cells in the striatum at postnatal day 1 (E) was not altered, but the total number of TUNEL ${ }^{+}$cells increased following neonatal lesions of connections and examined 1 day post-lesion (F). TUNEL ${ }^{+}$cells displayed typical ultrastructural features of apoptosis. Cells were shrunken, with a condensed cytoplasm and a pyknotic nucleus containing two chromatin clumps (G), or displaying a homogenously dark nucleus and a cytoplasm with condensed aggregates

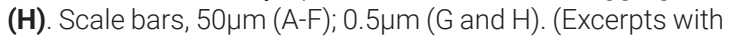
permission from Sophou et al., Eur J Neurosci. 24: 573-585, 2006; Zacharaki et al., Brain Research, 1344: 62-76, 2010). 

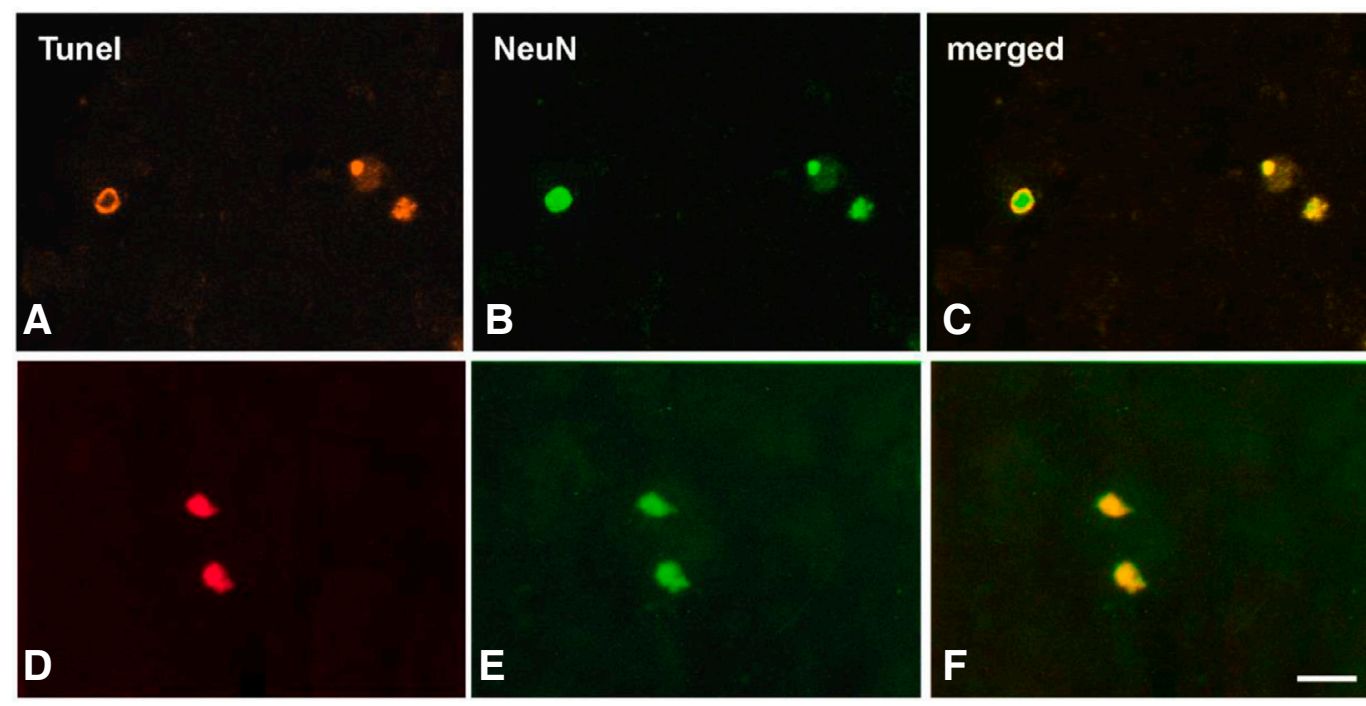

the first four postnatal weeks. Their frequency was high one week after birth and showed a single peak at P5 (Mellios et al., 2009). In the dorsal lateral geniculate nucleus (dLGN) of the thalamus, apoptosis occurs neonatally, with the highest density of dying cells at P1 (Zacharaki et al., 2010). Our data, together with evidence from other studies, suggest that apoptosis is an early postnatal event and is executed within the same developmental time window across brain areas. Indeed, in the SVZ, the proliferative layer of the developing cerebral cortex, apoptosis is most prominent at birth, involving one in every two newly generated cells (Thomaidou et al., 1997). The majority of pyramidal neurons in the rodent cerebral cortex undergo area- and layer-specific apoptosis between P2 and P5, whilst most interneurons die mainly between P5 and P10 (Wong and Marín, 2019). In the hippocampus, active caspase-3 expressing postmitotic neurons are mainly detected from P2 and reach maximum numbers at $\mathrm{P7}$ (Liu et al., 2008). In the cerebellar cortex, neuronal apoptosis occurs between P0 and P14, with layer-specific peaks during the first nine postnatal days (Cheng et al., 2011). In the external granular layer, apoptosis occurs in two phases, one affecting the precursors and pre-migratory, and the other the mature, migrating granule cells, whilst Purkinje cells die in the course of their generation and migration during the first postnatal week (Lossi et al., 2018). Apoptosis of immature dopaminergic neurons in the substantia nigra is also biphasic, with one peak at P2 and a second at P14 (Oo and Burke, 1997).

The temporal pattern of apoptosis in all brain areas examined parallels critical developmental events that involve the morphological and functional differentiation of postmitotic neurons and the establishment of reciprocal synaptic connections. Cholinergic projection neurons of the BF are generated in the embryonic lateral ganglionic eminence, already innervate their cortical targets at birth, and acquire mature features during the early postnatal period (Dinopoulos et al., 1989). This is also the period of maximal secretion of NGF that binds to the dependence receptor TrkA which is expressed in a population of cholinergic neurons in the BF (Sobreviela et al., 1994). Striatal GABAergic projection neurons and cholinergic interneurons are generated in the lateral ganglionic eminence during embryonic life, mature after birth (Rymar et al., 2004), and establish their afferent synaptic inputs early in postnatal life (Antonopoulos et al., 2002). Within this period, the dependence

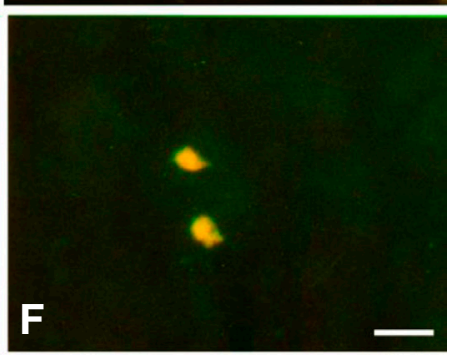

Fig. 5. Photomicrographs of doublelabeled apoptotic neurons in the developing dLGN. Normal animals at P1 (A, B, C) and neonatally lesioned animals at post-lesion day 1 (D, E, F) Merged images (C, F) depict TUNEL ${ }^{+}$ cells $(A, D)$ that are also labeled for NeuN, revealing their neuronal nature (B, E). Scale bar, $20 \mu \mathrm{m}$. (Re-used with permission from Zacharakietal., Brain Research, 1344: 62-76, 2010).

receptors TrkB and TrkC are expressed in the striatum (Escandón et al., 1994), and cortical-, as well as midbrain-derived neurotrophins, are expressed at high levels, supporting immature striatal neuron survival (Friedman et al., 1991; Baydyuk et al., 2013). Neurons in the dLGN are born during embryonic development and undergo an initial growth-burst during the first postnatal week (Parnavelas et al., 1977), when neuronal connections are formed through enhanced synaptogenesis (Kageyama and Robertson, 1993). It is noteworthy that apoptosis occurs during the pre-critical period of key developmental events, such as the organization of the geniculocortical mapping. These events in turn contribute to the activation of the critical period of experience-modulated plasticity (Huberman, 2007).

Collectively, these data strongly suggest that the most profound period of apoptosis correlates with the development of the brain cytoarchitecture, morphological differentiation of neurons, neurotransmitter expression and organization of functional neuronal networks. After neuronal maturation and incorporation into functional circuits is complete, the apoptotic pathway is inhibited. This is consistent with a recent notion that challenges the classical "neurotrophic theory" and suggests that neuronal activity that controls the expression of growth factors and apoptotic proteins, the neurotransmitter input and cell-intrinsic mechanisms related to the apoptotic machinery, are the regulators of apoptosis in the postnatal brain (Dekkers et al., 2013). Furthermore, it has been suggested that developmental reprogramming pathways restrict the apoptotic machinery in post-mitotic cells at molecular, transcriptional and metabolic levels (Hollville et al., 2019). Apoptosis may serve to match neuron numbers to the size of their target field and their afferent input, a process referred to as "systems matching" (Wong and Marín, 2019). Postnatal apoptosis affects proliferating precursors, and to a larger extent, postmitotic, postmigratory, immature neurons born at embryonic stages. According to previous reports, in proliferating or migrating populations, apoptosis may control cell numbers by eliminating excess, or defective, or misplaced cells (Wong and Marín, 2019).

In order to investigate how neuronal activity through neurotransmitter action affects the survival and death of neurons during this critical period of postnatal development, we performed lesions of connections of the rat brain areas examined previously, at around 
the time these connections are formed and at later stages, when neuronal circuits are fully mature (Sophou et al., 2006; Mellios et al., 2009; Zacharaki et al., 2010). The results of these studies showed that destruction of neuronal circuits during development does not induce consistent responses across different brain areas. In particular, neonatal cortical lesions affect the survival and differentiation of neurons in the striatum and the dLGN, but do not alter the viability of cholinergic projection neurons in the BF (Fig. 4). This regional specificity in lesion-induced apoptosis may be attributed to the neuron-type, the extent of connectivity affected, and the differential expression of dependence and non- dependence receptors in these areas.

It is noteworthy that de-afferentation of striatal and dLGN neurons at birth induces an apoptotic wave that is most dramatic one week post-lesion. The effect on cortical lesion-induced apoptosis of striatal and dLGN neurons is similar after destruction of catecholaminergic and retinal afferent systems, respectively. By contrast, lesions performed at later stages of development, when naturally occurring apoptosis is normally restricted, do not induce cell death in striatal neurons. The time window of neuronal vulnerability for dLGN neurons is similar, but spans the pre-critical period before eye opening. These data show a developmentally dependent ability of lesions of synaptic connections to induce neuronal apoptosis, implicating the existence of a crucial period during which connectivity-induced neuronal activity is essential for survival. This is consistent with various hypotheses that death-inducing factors are preferentially expressed in young neurons, while mature neurons acquire anti-apoptotic protective properties against any external stress (Pfisterer and Khodosevich, 2017).

\section{Acknowledgments}

Our research work presented in this review has been supported by the Greek Ministry of Development (General Secretariat of Research and Technology, PENED Grants: 95ED 217, 1995 and 99ED 322, 1999), the Greek Ministry of Education (HRAKLEITOS MIS 88722, 2002), the Research Committee of Aristotle University of Thessaloniki $(89289,2012)$ and Biohellenika A.E.

\section{References}

ANACKER C., HEN R. (2017). Adult hippocampal neurogenesis and cognitive flexibility - linking memory and mood. Nature Reviews Neuroscience 18: 335-346. https://doi.org/10.1038/nrn.2017.45

ALTMAN J., BAYER S. A. (1990). Migration and distribution of two populations of hippocampal granule cell precursors during the perinatal and postnatal periods. The Journal of Comparative Neurology 301: 365-381. https://doi.org/10.1002/ cne.903010304

AMBRosinI A., GRACIA M., PROAG A., RAYER M., MONIER B., SUZANNE M. (2017). Apoptotic forces in tissue morphogenesis. Mechanisms of Development 144: 33-42. https://doi.org/10.1016/j.mod.2016.10.001

ANDREWS W. D., DAVIDSON K., TAMAMAKI N., RUHRBERG C., PARNAVELAS J. G. (2016). Altered proliferative ability of neuronal progenitors in PlexinA1 mutant mice. Journal of Comparative Neurology 524: 518-534. https://doi.org/10.1002/ cne.23806

ANDREWS W. D., BARBER M., NEMITZ M., MEMI F., PARNAVELAS J. G. (2017). Semaphorin3A-neuropilin1 signalling is involved in the generation of cortical interneurons. Brain Structure and Function 222: 2217-2233. https://doi.org/10.1007/ s00429-016-1337-3

ANTONOPOULOS J., DORI I., DINOPOULOS A., CHIOTELLI M., PARNAVELAS J.G. (2002). Postnatal development of the dopaminergic system of the striatum in the rat. Neuroscience 110:245-256. https://doi.org/10.1016/S0306-4522(01)00575-9
BAYDYUK M., XIE Y., TESSAROLLO L., XU B. (2013). Midbrain-Derived Neurotrophins Support Survival of Immature Striatal Projection Neurons. Journal of Neuroscience 33: 3363-3369. https://doi.org/10.1523/JNEUROSCI.3687-12.2013

BEKIARI C., GIANNAKOPOULOU A., SISKOS N., GRIVAS I., TSINGOTJIDOU A., MICHALOUDI H., PAPADOPOULOS G. C. (2015a). Neurogenesis in the septal and temporal part of the adult rat dentate gyrus. Hippocampus 25: 511-523. https:// doi.org/10.1002/hipo.22388

BEKIARI C., GRIVAS I., GIANNAKOPOULOU A., MICHALOUDI-PAVLOU E., KOSTOPOULOS G., PAPADOPOULOS G. C. (2015b). Dentate gyrus variation along its septo-temporal axis: Structure and Function in Health and Disease. In Dentate Gyrus (Ed. Lowes Z.). Nova Science Publishers Inc., pp. 137-198.

BEKIARI C., GRIVAS I., TSINGOTJIDOU A., PAPADOPOULOS G. C. (2020). Adult neurogenesis and gliogenesis in the dorsal and ventral canine hippocampus. Journal of Comparative Neurology 528: 1216-1230. https://doi.org/10.1002/cne.24818

BERG D. A., SU Y., JIMENEZ-CYRUS D., PATEL A., HUANG N., MORIZET D., LEE S., SHAH R., RINGELING F. R., JAIN R., EPSTEIN J. A., WU Q.F., CANZAR S., MING G.L., SONG H., BOND A. M. (2019). A Common Embryonic Origin of Stem Cells Drives Developmental and Adult Neurogenesis. Cell 177: 654-668.e15. https:// doi.org/10.1016/j.cell.2019.02.010

BOLDRINI M., FULMORE C. A., TARTT A. N., SIMEON L. R., PAVLOVA I., POPOSKA V., ROSOKLIJA G. B., STANKOV A., ARANGO V., DWORK A. J., HEN R., MANN J. J. (2018). Human Hippocampal Neurogenesis Persists throughout Aging. Cell Stem Cell 22: 589-599.e5. https://doi.org/10.1016/j.stem.2018.03.015

BOND A. M., MING G., SONG H. (2015). Adult Mammalian Neural Stem Cells and Neurogenesis: Five Decades Later. Cell Stem Cell 17: 385-395. https://doi. org/10.1016/j.stem.2015.09.003

BRUS M., MEURISSE M., GHEUSI G., KELLER M., LLEDO P.M., LÉVY F. (2013). Dynamics of olfactory and hippocampal neurogenesis in adult sheep. Journal of Comparative Neurology 521: 169-188. https://doi.org/10.1002/cne.23169

BUREK M. J., OPPENHEIM R. W. (1996). Programmed Cell Death in the Developing Nervous System. Brain Pathology 6: 427-446. https://doi org/10.1111/j.1750-3639.1996.tb00874.x

CHANDLERK., DOSSO H., SIMARD S., SIDDIQIS., RUDYKC., SALMASO N. (2020). Differential Effects of Short-term Environmental Enrichment in Juvenile and Adult Mice. Neuroscience 429: 23-32. https://doi.org/10.1016/j.neuroscience.2019.12.028

CHARRIER J. B., LAPOINTEF., DOUARIN N. M. L., TEILLETM. A. (2001). Anti-apoptotic role of Sonic hedgehog protein at the early stages of nervous system organogenesis. Development 128:4011-4020. https://doi.org/10.1242/dev.128.20.4011

CHENG X. S., LI M. S., DU J., JIANG Q. Y., WANG L., YAN S. Y., YU D. M., DENG J. B (2011). Neuronal Apoptosis in the Developing Cerebellum. Anatomia, Histologia, Embryologia 40: 21-27. https://doi.org/10.1111/j.1439-0264.2010.01033.x

DEKKERS M. P. J., BARDE Y.A. (2013). Programmed Cell Death in Neuronal Development. Science 340: 39-41. https://doi.org/10.1126/science.1236152

DEKKERS M. P. J., NIKOLETOPOULOU V., BARDE Y. A. (2013). Death of developing neurons: New insights and implications for connectivity. Journal of Cell Biology 203: 385-393. https://doi.org/10.1083/jcb.201306136

DINOPOULOS A., EADIE L. A., DORI I., PARNAVELAS J. G. (1989). The development of basal forebrain projections to the rat visual cortex. Experimental Brain Research 76: 563-571. https://doi.org/10.1007/BF00248913

DORI I., PETRAKIS S., GIANNAKOPOULOU A., BEKIARI C., GRIVAS I., SISKA E. K., KOLIAKOS G., PAPADOPOULOS G. C. (2017). Seven days post-injury fate and effects of genetically labelled adipose-derived mesenchymal cells on a rat traumatic brain injury experimental model. Histology and histopathology 32: 1041 1055. https://doi.org/10.14670/HH-11-864

ELKOURIS M., BALASKAS N., POULOU M., POLITIS P. K., PANAYIOTOU E., MALAS S., THOMAIDOU D., REMBOUTSIKAE. (2011). Sox1 Maintains the Undifferentiated State of Cortical Neural Progenitor Cells via the Suppression of Prox1-Mediated Cell Cycle Exit and Neurogenesis. Stem Cells 29: 89-98. https://doi.org/10.1002/ stem.554

ENGLER A., ZHANG R., TAYLOR V. (2018). Notch and Neurogenesis. In Molecular Mechanisms of Notch Signaling (Ed. Borggrefe T., Giaimo B. D.). Advances in Experimental Medicine and Biology, Vol. 1066. Springer International Publishing, Cham, pp. 223-234. https://doi.org/10.1007/978-3-319-89512-3_11

ERIKSSON P. S., PERFILIEVA E., BJÖRK-ERIKSSON T., ALBORN A. M., NORDBORG C., PETERSON D. A., GAGE F. H. (1998). Neurogenesis in the adult human hippocampus. Nature Medicine 4: 1313-1317. https://doi.org/10.1038/3305 
ESCANDON E., SOPPET D., ROSENTHAL A., MENDOZA-RAMIREZ J.L., SZONYI E., BURTON L.E., HENDERSON C.E., PARADA L.F., NIKOLICS K. (1994). Regulation of neurotrophin receptor expression during embryonic and postnatal development. The Journal of Neuroscience 14: 2054-2068. https://doi.org/10.1523/ JNEUROSCI.14-04-02054.1994

FRIEDMAN W.J., ERNFORS P., PERSSON H. (1991). Transient and persistent expression of NT-3/HDNF mRNA in the rat brain during postnatal development. The Journal of Neuroscience 11: 1577-1584. https://doi.org/10.1523/JNEUROSCl.11-06-01577.1991

GALLUZZI L., VITALE I. (2018). Oncogene-induced senescence and tumour control in complex biological systems. Cell Death \& Differentiation 25: 1005-1006. https:// doi.org/10.1038/s41418-018-0102-y

GÖTZ M., HUTTNER W. B. (2005). The cell biology of neurogenesis. Nature Reviews Molecular Cell Biology 6: 777-788. https://doi.org/10.1038/nrm1739

GRIFFITHS B.B., BHUTANI A., STARY C.M. (2020). Adult neurogenesis from reprogrammed astrocytes. Neural Regeneration Research 15: 973. https://doi. org/10.4103/1673-5374.270292

GRIVASI., MICHALOUDI H., BATZIOS C., CHIOTELLI M., PAPATHEODOROPOULOS C., KOSTOPOULOS G., PAPADOPOULOS G.C. (2003). Vascular network of the rat hippocampus is not homogeneous along the septotemporal axis. Brain Research 971: 245-249. https://doi.org/10.1016/S0006-8993(03)02475-2

HERNÁNDEZ-MIRANDA L. R., PARNAVELAS J. G., CHIARA F. (2010). Molecules and Mechanisms Involved in the Generation and Migration of Cortical Interneurons. ASN Neuro 2: AN20090053. https://doi.org/10.1042/AN20090053

HEVNER R. F. (2019). Intermediate progenitors and Tbr2 in cortical development. Journal of Anatomy 235: 616-625. https://doi.org/10.1111/joa.12939

HOLLVILLEE., ROMERO S. E., DESHMUKHM. (2019). Apoptotic cell death regulation in neurons. The FEBS Journal 286:3276-3298. https://doi.org/10.1111/febs.14970

HUBERMAN A. D. (2007). Mechanisms of eye-specific visual circuit development. Current Opinion in Neurobiology 17:73-80. https://doi.org/10.1016/j.conb.2007.01.005

IKONOMIDOU C. (2009). Triggers of apoptosis in the immature brain. Brain and Development 31: 488-492. https://doi.org/10.1016/j.braindev.2009.02.006

ISAEV N. K., STELMASHOOK E. V., GENRIKHS E. E. (2019). Neurogenesis and brain aging. Reviews in the Neurosciences 30: 573-580. https://doi.org/10.1515/ revneuro-2018-0084

JUNG A., KIM T. W., RHYU I. J., KIM H., LEE Y. D., VINSANT S., OPPENHEIM R. W., SUN W. (2008). Misplacement of Purkinje Cells during Postnatal Development in Bax Knock-Out Mice: A Novel Role for Programmed Cell Death in the Nervous System?. Journal of Neuroscience 28: 2941-2948. https://doi.org/10.1523/ JNEUROSCI.3897-07.2008

JURAVER-GESLIN H. A., DURAND B. C. (2015). Early development of the neural plate: New roles for apoptosis and for one of its main effectors caspase-3. genesis 53 : 203-224. https://doi.org/10.1002/dvg.22844

JURKOWSKI M. P., BETTIO L., K. WOO E., PATTEN A., YAU S.Y., GIL-MOHAPEL J. (2020). Beyond the Hippocampus and the SVZ: Adult Neurogenesis Throughout the Brain. Frontiers in Cellular Neuroscience 14: 576444. https://doi.org/10.3389/ fncel.2020.576444

KAGEYAMA G. H., ROBERTSON R. T. (1993). Development of gemculocortical projections to visual cortex in rat: Evidence for early Ingrowth and synaptogenesis. The Journal of Comparative Neurology 335: 123-148. https://doi.org/10.1002/ cne. 903350109

KERR J. F. R., WYLLIE A. H., CURRIE A. R. (1972). Apoptosis: A Basic Biological Phenomenon with Wideranging Implications in Tissue Kinetics. British Journal of Cancer 26: 239-257. https://doi.org/10.1038/bjc.1972.33

KOHLER S. J., WILLIAMS N. I., STANTON G. B., CAMERON J. L., GREENOUGH W. T. (2011). Maturation time of new granule cells in the dentate gyrus of adult macaque monkeys exceeds six months. Proceedings of the National Academy of Sciences 108: 10326-10331. https://doi.org/10.1073/pnas.1017099108

LINDSTEN T., ROSS A. J., KING A., ZONG W.X., RATHMELL J. C., SHIELS H. A., ULRICH E., WAYMIRE K. G., MAHAR P., FRAUWIRTH K., CHEN Y., WEI M., ENG V. M., ADELMAN D. M., SIMON M.C., MA A., GOLDEN J. A., EVAN G., KORSMEYER S. J., MACGREGOR G. R., THOMPSON C. B. (2000). The Combined Functions of Proapoptotic Bcl-2 Family Members Bak and Bax Are Essential for Normal Development of Multiple Tissues. Molecular Cell 6: 1389-1399. https:// doi.org/10.1016/S1097-2765(00)00136-2
LIU J. P., CHANG L. R., GAO X. L., WU Y. (2008). Different expression of caspase-3 in rat hippocampal subregions during postnatal development. Microscopy Research and Technique 71: 633-638. https://doi.org/10.1002/jemt.20600

LOSSI L., CASTAGNA C., MERIGHI A. (2018). Caspase-3 Mediated Cell Death in the Normal Development of the Mammalian Cerebellum. International Journal of Molecular Sciences 19: 3999. https://doi.org/10.3390/ijms19123999

MELLIOS K., ZACHARAKI T., SOPHOU S., LATSARI M., ANTONOPOULOS J., DINOPOULOS A., PARNAVELAS J.G., DORI I. (2009). Natural and lesion-induced apoptosis in the rat striatum during development. Brain Research 1252: 30-44. https://doi.org/10.1016/j.brainres.2008.10.031

MEMI F., KILLEN A. C., BARBER M., PARNAVELAS J. G., ANDREWS W. D. (2019). Cadherin 8 regulates proliferation of cortical interneuron progenitors. Brain Structure and Function 224:277-292. https://doi.org/10.1007/s00429-018-1772-4

MIHALAS A. B., HEVNER R. F. (2017). Control of Neuronal Development by T-Box Genes in the Brain. In T-box Genes in Development (Ed. Frasch M.). Current Topics in Developmental Biology, Vol. 122. Elsevier, pp. 279-312. https://doi.org/10.1016/ bs.ctdb.2016.08.001

MIHALAS A. B., HEVNER R. F. (2018). Clonal analysis reveals laminar fate multipotency and daughter cell apoptosis of mouse cortical intermediate progenitors. Development 145: dev164335. https://doi.org/10.1242/dev.164335

MIRA H., MORANTE J. (2020). Neurogenesis From Embryo to Adult - Lessons From Flies and Mice. Frontiers in Cell and Developmental Biology 8: 533. https://doi. org/10.3389/fcell.2020.00533

MIZRAK D., LEVITIN H. M., DELGADO A. C., CROTET V., YUAN J., CHAKERZ., SILVAVARGAS V., SIMS P. A., DOETSCH F. (2019). Single-Cell Analysis of Regional Differences in Adult V-SVZ Neural Stem Cell Lineages. Cell Reports 26: 394-406. e5. https://doi.org/10.1016/j.celrep.2018.12.044

MIZUTANI K., YOON K., DANG L., TOKUNAGA A., GAIANO N. (2007). Differential Notch signalling distinguishes neural stem cells from intermediate progenitors. Nature 449: 351-355. https://doi.org/10.1038/nature06090

NIKLISON-CHIROU M. V., AGOSTINI M., AMELIO I., MELINO G. (2020). Regulation of Adult Neurogenesis in Mammalian Brain. International Journal of Molecular Sciences 21: 4869. https://doi.org/10.3390/ijms21144869

NIKOLETOPOULOU V., LICKERT H., FRADE J. M., RENCUREL C., GIALLONARDO P., ZHANG L., BIBEL M., BARDE Y.A. (2010). Neurotrophin receptors TrkA and TrkC cause neuronal death whereas TrkB does not. Nature 467: 59-63. https:// doi.org/10.1038/nature09336

NONOMURA K., YAMAGUCHIY., HAMACHIM., KOIKEM.,UCHIYAMA Y., NAKAZATO K., MOCHIZUKI A., SAKAUE-SAWANO A., MIYAWAKI A., YOSHIDA H., KUIDA K. MIURA M. (2013). Local Apoptosis Modulates Early Mammalian Brain Development through the Elimination of Morphogen-Producing Cells. Developmental Cell 27: 621-634. https://doi.org/10.1016/j.devcel.2013.11.015

OBERNIER K., ALVAREZ-BUYLLA A. (2019). Neural stem cells: origin, heterogeneity and regulation in the adult mammalian brain. Development 146: dev156059. https://doi.org/10.1242/dev.156059

OO T. F., BURKE R. E. (1997). The time course of developmental cell death in phenotypically defined dopaminergic neurons of the substantia nigra. Developmental Brain Research 98: 191-196. https://doi.org/10.1016/S0165-3806(96)00173-3

OZAIR M. Z., KINTNER C., BRIVANLOU A. H. (2013). Neural induction and early patterning in vertebrates. Wiley Interdisciplinary Reviews: Developmental Biology 2: 479-498. https://doi.org/10.1002/wdev.90

PANCHISION D. M., MCKAY R. D.G. (2002). The control of neural stem cells by morphogenic signals. Current Opinion in Genetics \& Development 12: 478-487. https://doi.org/10.1016/S0959-437X(02)00329-5

PARNAVELAS J. G., ALIFRAGIS P., NADARAJAH B. (2002). The origin and migration of cortical neurons. In Changing Views of Cajal's Neuron. Progress in Brain Research, Vol. 136. Elsevier, pp. 73-80. https://doi.org/10.1016/S0079-6123(02)36008-4

PARNAVELAS J. G., DINOPOULOS A., DAVIES S. W. (1989). The central visual pathways. In Handbook of Chemical Neuroanatomy, Integrated Systems of the CNS (Ed. Björklund A., Hökfelt T., Swanson L. W.). Vol. 7. Elsevier, Amsterdam, pp. 1-164.

PARNAVELAS J. G., MOUNTY E. J., BRADFORD R., LIEBERMAN A. R. (1977). The postnatal development of neurons in the dorsal lateral geniculate nucleus of the rat: A Golgi study. The Journal of Comparative Neurology 171: 481-499. https:// doi.org/10.1002/cne.901710405

PFISTERER U., KHODOSEVICH K. (2017). Neuronal survival in the brain: neuron type-specific mechanisms. Cell Death \& Disease 8: e2643-e2643. https://doi. org/10.1038/cddis.2017.64 
PILAZ L.J., MCMAHON J. J., MILLER E. E., LENNOX A. L., SUZUKI A., SALMON E., SILVER D. L. (2016). Prolonged Mitosis of Neural Progenitors Alters Cell Fate in the Developing Brain. Neuron 89:83-99. https://doi.org/10.1016/j.neuron.2015.12.007

PLACZEK M., BRISCOE J. (2018). Sonic hedgehog in vertebrate neural tube development. The International Journal of Developmental Biology 62: 225-234. https:// doi.org/10.1387/ijdb.170293jb

RAKIC P. (2003). Developmental and Evolutionary Adaptations of Cortical Radial Glia. Cerebral Cortex 13: 541-549. https://doi.org/10.1093/cercor/13.6.541

RYMAR V. V., SASSEVILLE R., LUK K. C., SADIKOT A. F. (2004). Neurogenesis and stereological morphometry of calretinin-immunoreactive GABAergic interneurons of the neostriatum. The Journal of Comparative Neurology 469: 325-339. https:// doi.org/10.1002/cne.11008

SEKI T., SATO T., TODA K., OSUMI N., IMURA T., SHIODA S. (2014). Distinctive population of Gfap-expressing neural progenitors arising around the dentatenotch migrate and form the granule cell layer in the developing hippocampus . Journal of Comparative Neurology 522: Spc1-Spc1. https://doi.org/10.1002/cne.23508

SIWAK-TAPP C. T., HEAD E., MUGGENBURG B. A., MILGRAM N. W., COTMAN C. W. (2007). Neurogenesis decreases with age in the canine hippocampus and correlates with cognitive function. Neurobiology of Learning and Memory 88: 249-259. https://doi.org/10.1016/j.nlm.2007.05.001

SMITH J. (1997). Neurulation: coming to closure. Trends in Neurosciences 20: 510517. https://doi.org/10.1016/S0166-2236(97)01121-1

SNYDER J. S., CHOE J. S., CLIFFORD M. A., JEURLING S. I., HURLEY P., BROWN A., KAMHI J. F., CAMERON H. A. (2009). Adult-Born Hippocampal Neurons Are More Numerous, Faster Maturing, and More Involved in Behavior in Rats than in Mice. Journal of Neuroscience 29: 14484-14495. https://doi.org/10.1523/ JNEUROSCI.1768-09.2009

SNYDER J. S., FERRANTE S. C., CAMERON H. A. (2012). Late Maturation of AdultBorn Neurons in the Temporal Dentate Gyrus. PLoS ONE 7: e48757. https://doi. org/10.1371/journal.pone.0048757

SOBREVIELA T., CLARY D. O., REICHARDT L. F., BRANDABUR M. M., KORDOWER J. H., MUFSON E. J. (1994). TrkA-immunoreactive profiles in the central nervous system: Colocalization with neurons containing $\mathrm{p} 75$ nerve growth factor receptor, choline acetyltransferase, and serotonin. Journal of Comparative Neurology 350: 587-611. https://doi.org/10.1002/cne.903500407

SOPHOU S., DORI I., ANTONOPOULOS J., PARNAVELAS J. G., DINOPOULOS A. (2006). Apoptosis in the rat basal forebrain during development and following lesions of connections. European Journal of Neuroscience 24: 573-585. https:// doi.org/10.1111/j.1460-9568.2006.04929.x

SORRELLS S. F., PAREDES M. F., ZHANG Z., KANG G., PASTOR-ALONSO O., BIAGIOTTI S., PAGE C. E., SANDOVAL K., KNOX A., CONNOLLY A., HUANG E. J., GARCIA-VERDUGO J. M., OLDHAM M. C., YANG Z., ALVAREZ-BUYLLA A. (2021). Positive Controls in Adults and Children Support That Very Few, If Any, New Neurons Are Born in the Adult Human Hippocampus. The Journal of Neuroscience 41: 2554-2565. https://doi.org/10.1523/JNEUROSCI.0676-20.2020
SPALDING K. L., BERGMANN O., ALKASS K., BERNARD S., SALEHPOUR M., HUTTNER H. B., BOSTRÖM E., WESTERLUNDI., VIALC., BUCHHOLZB. A., POSSNERT G., MASH D. C., DRUID H., FRISÉN J. (2013). Dynamics of Hippocampal Neurogenesis in Adult Humans. Cell 153: 1219-1227. https://doi.org/10.1016/j. cell.2013.05.002

TAVERNA E., GÖTZ M., HUTTNER W. B. (2014). The Cell Biology of Neurogenesis: Toward an Understanding of the Development and Evolution of the Neocortex. Annual Review of Cell and Developmental Biology 30: 465-502. https://doi. org/10.1146/annurev-cellbio-101011-155801

THOMAIDOU D., MIONE M. C., CAVANAGH J. F. R., PARNAVELAS J. G. (1997) Apoptosis and Its Relation to the Cell Cycle in the Developing Cerebral Cortex. The Journal of Neuroscience 17: 1075-1085. https://doi.org/10.1523/JNEUROSCI.17-03-01075.1997

UZQUIANO A., GLADWYN-NG I., NGUYEN L., REINER O., GÖTZ M., MATSUZAKI F., FRANCIS F. (2018). Cortical progenitor biology: key features mediating proliferation versus differentiation. Journal of Neurochemistry 146: 500-525. https://doi. org/10.1111/jnc. 14338

VALLENDER E. J., LAHN B. T. (2006). A primate-specific acceleration in the evolution of the caspase-dependent apoptosis pathway. Human Molecular Genetics 15: 3034-3040. https://doi.org/10.1093/hmg/ddl245

VIEIRA C., POMBERO A., GARCIA-LOPEZ R., GIMENO L., ECHEVARRIA D., MARTINEZ S. (2010). Molecular mechanisms controlling brain development: an overview of neuroepithelial secondary organizers. The International Journal of Developmental Biology 54: 7-20. https://doi.org/10.1387/ijdb.092853cv

VILLALBA A., GÖTZ M., BORRELL V. (2021). The regulation of cortical neurogenesis. In Molecular Mechanisms of Neural Development and Insights into Disease (Ed Bashaw G. J.). Current Topics in Developmental Biology, Vol. 142. Elsevier, pp. 1-66. https://doi.org/10.1016/bs.ctdb.2020.10.003

WILSON S. W., HOUART C. (2004). Early Steps in the Development of the Forebrain. Developmental Cell 6: 167-181. https://doi.org/10.1016/S1534-5807(04)00027-9

WONG F. K., MARÍN O. (2019). Developmental Cell Death in the Cerebral Cortex. Annual Review of Cell and Developmental Biology 35: 523-542. https://doi.org/10.1146/ annurev-cellbio-100818-125204

WU M. V., HEN R. (2014). Functional dissociation of adult-born neurons along the dorsoventral axis of the dentate gyrus. Hippocampus 24: 751-761. https://doi. org/10.1002/hipo.22265

YEO W., GAUTIER J. (2004). Early neural cell death: dying to become neurons. Developmental Biology 274: 233-244. https://doi.org/10.1016/j.ydbio.2004.07.026

ZACHARAKIT., SOPHOUS., GIANNAKOPOULOU A., DINOPOULOSA., ANTONOPOULOS J., PARNAVELAS J.G., DORI I. (2010). Natural and lesion-induced apoptosis in the dorsal lateral geniculate nucleus during development. Brain Research 1344: 62-76. https://doi.org/10.1016/j.brainres.2010.05.021

ZOCHER S., SCHILLING S., GRZYB A. N., ADUSUMILLI V. S., BOGADO LOPES J., GÜNTHER S., OVERALL R. W., WINTER Y., KEMPERMANN G. (2020). Early-life environmental enrichment generates persistent individualized behavior in mice. Science Advances 6: eabb1478. https://doi.org/10.1126/sciadv.abb1478 